\title{
Ressonâncias entre cinema, cantos e corpos no filme As Hipermulheres ${ }^{1}$
}

Bernard Belisário

Resumo: Neste artigo, propomos uma análise do documentário brasileiro As Hipermulheres (2011) a fim de descrever o modo como os cantos rituais participam da mise-en-scène dos sujeitos filmados e da própria câmera. O filme aborda a realização do Jamugikumalu, o grande ritual feminino do Alto Xingu. Indispensáveis para a realização do cerimonial, os cantos aparecem no filme como motor de muitas das performances filmadas. Buscamos então na sua mise-en-scène documentária as relações entre a forma sonoro-musical dos cantos, os corpos dos sujeitos em cena e os movimentos da câmera em cena.

Palavras-chave: documentário; cinema indígena; Kuikuro; mise-en-scène.

Abstract: Resonances among cinema, chants and bodies in the film The Hyperwomen - This paper analyzes the Brazilian documentary The Hyperwomen (2011) to describe the way the ritual chants take part in the setting of the persons filmed, as well as the camera itself. The film approaches the making of Jamugikumalu, the great female ritual at Alto Xingu. The chants, indispensable to the solemn liturgy, come up with the film as a mover of many registered performances. This text searches on the documented setting for those possible relations existing among the chants' sonorous-musical form, the bodies of the persons on focus, and the movements of the camera while recording.

Keywords: documentary; indigenous cinema; Kuikuro; mise-en-scène.

Em 2011 estreava no circuito de festivais nacionais o longa-metragem As Hipermulheres. Rodado na aldeia Ipatse dos índios Kuikuro, localizada no Parque Indígena do Xingu (Mato Grosso - Brasil), o filme aborda a realização do grande ritual

1 Este artigo retoma e desenvolve algumas das questões inicialmente elaboradas em nossa dissertação de mestrado (BELISÁRIO, 2014), posteriormente apresentadas no $19^{\circ}$ Encontro da Sociedade Brasileira de Estudos de Cinema e Audiovisual - Socine (BELISÁRIO, 2015). Além dos coordenadores e dos participantes do seminário temático Cinema e Ciências Sociais da Socine, agradeço também à pesquisadora Rosângela de Tugny e aos amigos do Grupo de Pesquisa Poéticas da Experiência (UFMG/CNPq) pela interlocução preciosa. 
feminino do Alto Xingu², o Jamugikumalu, e tem como mote a transmissão dos cantos tradicionais indispensáveis à realização do ritual, nos quais somente uma mulher, a eginhoto (mestre ou "dona" dos cantos) Kanu, conhece em sua totalidade. Entretanto, ela encontra-se doente, o que passa a mobilizar uma série de providências e preocupações por parte não só de seus familiares como também dos organizadores da festa e dos habitantes da aldeia.

A direção do longa é assinada pelo realizador indígena Takumã Kuikuro, pelo antropólogo Carlos Fausto e pelo oficineiro formado no projeto Vídeo nas Aldeias, Leonardo Sette. A produção executiva de Vincent Carelli e Carlos Fausto revela a continuidade de uma parceria já consolidada entre a ONG Vídeo nas Aldeias e o Museu Nacional/UFRJ, com o projeto Documenta Kuikuro, a partir do qual foram produzidos anteriormente os premiados documentários O dia em que a lua menstruou (2004) e Cheiro de pequi (2006), ambos dirigidos por Takumã Kuikuro e seus colegas do Coletivo Kuikuro de Cinema.

As oficinas de formação do projeto Vídeo nas Aldeias na aldeia dos Kuikuro tiveram início em 2002 e, também ali, os rituais apareceram como vetores importantes desta dinâmica de invenção da cultura com o cinema. Conforme explica Carlos Fausto (2011), um dos coordenadores do projeto de documentação, o cacique e as lideranças da aldeia já tinham a demanda do registro de seus rituais, cantos e mitos, para que pudessem assim "guardar a sua cultura". Aqueles primeiros documentários realizados pelos jovens cineastas Kuikuro abordam justamente a realização do ritual Ahugagü do pequi e as ritualizações acerca de um eclipse lunar.

Entre 2003 e 2010, Takumã e os jovens do Coletivo Kuikuro de Cinema - grupo inicialmente formado pelos participantes das oficinas de vídeo, e que posteriormente foi (e continua) recebendo novos integrantes - realizaram uma série de filmes, quase todos desconhecidos do público não indígena, em que registram suas festas e rituais. A circulação desses filmes geralmente se restringe às sessões noturnas de cinema no pátio central da aldeia ou aos momentos em que o gerador de energia elétrica principal é ligado, e as sessões ocorrem dentro das casas equipadas com aparelho reprodutor de DVD e televisão.

Ao contrário do que se tem dito sobre esses "filmes da aldeia", não se trata aqui do material bruto, assistido integralmente sem nenhuma edição. Os longos planossequência das performances geralmente são encadeados de modo a manter a coerência com que são apresentadas no próprio ritual. Certamente o pensamento que organiza e articula as sequências das performances nesses filmes é bem diferente daquele dos filmes feitos para o público não indígena. Se, por um lado, é na montagem que os "filmes da aldeia" se diferenciam dos filmes destinados à exibição em festivais, por outro, é em sua mise-en-scène que podemos encontrar um modo comum de filmar o ritual.

2 A bacia do Alto Xingu compreende a região dos seus principais formadores, os rios Culuene, Curisevo, Batovi e Ronuro. Segundo o arqueólogo Michael Heckengerger (2001), as primeiras ocupações de que se tem notícia nesta região datam de 800 a 900 d.C. 


\title{
Os cantos em cena
}

Para que a noção de mise-en-scène ganhe uma dimensão operatória na análise fílmica é preciso indicar quais elementos em jogo na cena poderiam descrever os modos como o filme e o mundo se relacionam. Conforme a própria narrativa de As Hipermulheres sugere, não seria possível realizar o ritual Jamugikumalu sem uma experiente mestra de cantos. Tomamos então o canto como elemento central de nossa análise, tanto nas cenas preparatórias em que as mulheres Kuikuro os ensaiam, aprendem, rememoram e ensinam, quanto nas cenas das performances do ritual propriamente dito.

Um primeiro traço deste devir-personagem do filme, em que se lançam os sujeitos diante da câmera, parece referir-se precisamente aos modos como os cantos constituem uma importante componente daquilo que Jean-Louis Comolli descreveu como auto-mise-en-scène ${ }^{3}$ :

\begin{abstract}
A auto-mise-en-scène seria a combinação de dois movimentos. Um vem do habitus e passa pelo corpo (o inconsciente) do agente como representante de um ou de vários campos sociais. O outro tem a ver com o fato de que o sujeito filmado, o sujeito em vista do filme (a 'profilmia' de Souriau), se destina ao filme, conscientemente e inconscientemente, se impregna dele, se ajusta à operação de cinematografia, nela coloca em jogo sua própria mise-en-scène, no sentido da colocação do corpo sob o olhar, do jogo do corpo no espaço e no tempo definidos pelo olhar do outro (a cena) (COMOLLI, 2008, p.85).
\end{abstract}

Há duas cenas que exemplificam bem os modos como o canto pode participar desse duplo movimento. Uma delas é a cena em que o velho Kamankgagü capina uma trilha quase tomada pelo mato. Primeiramente o canto surge como um fraco assobio que se mistura com o som da percussão da enxada e das folhas que se arrastam no chão. Na medida em que a câmera sustenta a duração da sua ação, Kamankgagü modifica sua mise-en-scène e passa a solfejar o canto, dando-Ihe um novo contorno. Seu trabalho passa a ser cada vez mais entrecortado por pausas nas quais o velho Kuikuro se deixa tomar pelo canto. O ápice desta transformação que o canto opera não só no espaço sonoro da cena, mas na própria mise-en-scène de Kamankgagü, se dá quando ele interrompe completamente a capina para cantar. Nesse momento, ele se projeta numa dança, seu corpo descreve gestos e movimentos que nada têm a ver com o trabalho que vinha desempenhando em cena. Ao incorporar o canto como componente principal de sua mise-en-scène, Kamankgagü se dispõe diante da câmera de uma maneira completamente nova. É neste sentido que o canto se apresenta como um vetor determinante deste devirpersonagem do filme que compõe a auto-mise-en-scène.

3 Na verdade, esse conceito foi inicialmente elaborado por Claudine de France, para quem tratar-se-ia de uma "noção essencial em cinematografia documentária, que define as diversas maneiras pelas quais o processo observado se apresenta por si mesmo ao cineasta no espaço e no tempo. Esta mise-en-scène própria, autônoma, em virtude da qual as pessoas filmadas mostram de maneira mais ou menos ostensiva, ou dissimulam a outrem, seus atos e as coisas que a envolvem" (FRANCE, 1998, p.405). 
Outra cena que mereceria nossa atenção é a performance ritual do canto de Kamatahigagi, em que Kanu dança e canta sozinha no pátio da aldeia em frente à sua casa. Nessa performance, a mestra de cantos dos Kuikuro percute o pé direito no chão num movimento coreográfico que avança e retrocede, conjugado como um movimento arquejado dos braços que ora suspendem uma flecha, ora outra.

Em sua breve reflexão acerca da relação entre o cinema e as mise-en-scène sociais, François Albéra (2000) chama atenção para o modo como os corpos são convocados nos rituais:

No seio destas mise-en-scènes sociais, existem casos forçosamente bastante coercitivos, quase impossíveis de reformular livremente, metaforicamente ou não: são aqueles dos rituais. Eles oferecem de fato uma mise-en-scène 'global' e não somente aquela de um gesto ou de um comportamento (ALBÉRA, 2000, p. 230).

Não há dúvida de que existam situações extremamente coercitivas no ritual em cena, como por exemplo a sequência da recepção dos convidados, em que uma das filhas de Kamankgagü precisa substituir sua mãe na entrega do alimento e dos discursos cerimoniais. Nessa cena, parece haver uma dupla coerção: uma delas vem do próprio ritual que, sob o olhar atento dos participantes, deve ser executado segundo uma série de parâmetros os quais a jovem Kehesu aparentemente desconhece; a outra vem do fato de que toda esta performance está sendo filmada, ou seja, é também outro tipo de espectador que está em jogo naquele momento: o espectador de cinema. ${ }^{4}$ Ainda que a performance de Kanu descrita acima esteja sujeita a essas mesmas condições, o que vemos em cena se parece muito pouco com uma situação de coerção. Embora haja uma componente que parte do ritual, e que é determinante na elaboração de sua mise-en-scène, não poderíamos dizer que não exista ali nenhum movimento de invenção que partiria da própria Kanu. Nesse caso, a liberdade com que a mestra de cantos se lança em seu devir fílmico não diz respeito a um vetor que a faria escapar da mise-en-scène própria do ritual, pelo contrário, está precisamente no virtuosismo com que executa seu canto e sua dança diante da câmera e dos espectadores da aldeia - o seu traço singular. A performance do virtuose não seria então aquela que recusa a partitura, tampouco a que se submete a ela de forma mecânica, mas aquela capaz de fazer do corpo do performer outro corpo, na medida em que ele se lança num campo de ressonâncias com as forças que a música é capaz de carregar e que a partitura não pode senão indicar.

Ha ainda outra sequência em que podemos perceber como o canto agencia a voz e o corpo dos sujeitos em cena, mesmo fora do ritual. Trata-se da cena em que Aulá caminha por uma trilha na mata enquanto rememora um dos cantos que, segundo ela

4 "Cinema: relação ao mesmo tempo regulada e aberta, organizada e aleatória, entre um conjunto composto de estímulos, sinais, signos e um espectador (ao menos) que faz parte deste conjunto (suposto, imaginado por ele - e não programado). Ao contrário dos esquemas simplistas que as 'teorias da comunicação' tanto insistiram em nos impor, não há, de um lado, uma 'emissão' e, de outro (...), uma 'recepção', mas um espectador incluído no processo de constituição do espetáculo, agindo sobre ele pelo interior" (COMOLLI, 2008, p.161). 
mesma, insistem em voltar para "dentro" de seu pai, quem Ihes ensinara. Nesse planosequência, escutamos bem de perto a melodia sussurrada em meio aos sons da floresta e de seus passos na terra. Ao longo desse percurso musical, nota-se que o som de seus passos compõe com a melodia cantada algo mais que um fundo sonoro indistinto. Os passos da personagem vão inscrevendo um elemento percussivo à melodia, criando assim uma nova componente rítmica ao canto, conforme descrevemos no diagrama analítico (Figura 1).

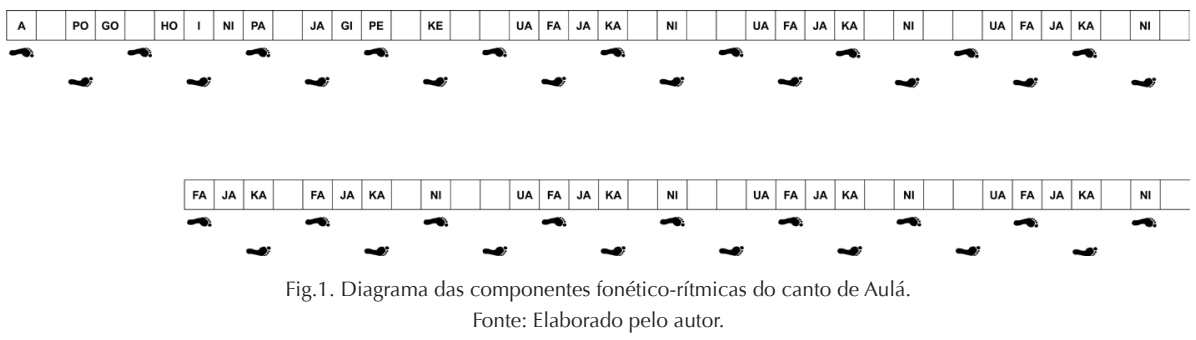

É como se o canto agenciasse não só sua voz, mas também seus pés, que tornam-se um instrumento percussivo: devir-tambor dos pés. Não seria então somente a voz que é tomada por um vetor que a lança para fora do território da linguagem (DELEUZE; GUATTARI, 1997, p.103), os próprios pés e pernas vão perdendo sua função de caminhar ao se integrarem a esse sistema de ressonâncias que os cantos agenciam (tenha-se em vista as várias performances do filme em que a coreografia das mulheres descreve um movimento de vaivém).

Outro aspecto que a análise dos cantos na mise-en-scène documentária de As Hipermulheres pode alcançar é o modo como estes mobilizam as relações entre os sujeitos em cena, especialmente nas sequências de transmissão e aprendizagem. Em uma delas, o velho Kamankgagü ensina para sua filha alguns dos cantos indicados num artefato peculiar: um molho de cordinhas de buriti repleto de nós, cada um referindo-se a um dos cantos que compõem aqueles conjuntos. Deitada em sua rede e com sua filha sobre o peito, Aulá escuta com atenção os cantos que seu pai tenta Ihe ensinar. Entretanto sua escuta não se restringe a ouvi-los, em um dado momento, ela acompanha um dos cantos articulando sua boca como se também cantasse, em silêncio.

Se pudermos analisar os cantos das mulheres Kuikuro separando suas componentes rítmicas, fonéticas e melódicas, diríamos que esse canto estabelece entre Kamankgagü e Aulá um campo de ressonâncias rítmico-fonético (ou quase, pois, a rigor, não há phoné, o som da voz), enquanto que, no plano melódico, ainda não pode encontrar ressonância no corpo de sua filha. Conforme menciona o próprio Kamankgagü em uma sequência enigmática - em que caminha numa trilha a caminho da lagoa, passando a explicar (sem contudo direcionar o olhar para o antecampo) de quem aprendera o canto que 
executa em cena -, os cantos ficam guardados no ventre do mestre de cantos. Podemos pensar então que seu aprendizado implicaria um trabalho no próprio corpo, para que estes não lhe "escapem". Seria preciso moldar (ou modular) o corpo aos cantos, fazendo em seu ventre a sua contraforma. Trabalho este que pode levar décadas a depender da quantidade de conjuntos de cantos rituais que o mestre de cantos almeja possuir.

Há outra circunstância, ainda nessa sequência de transmissão, na qual podemos perceber esse mesmo efeito de ressonância entre os corpos. Trata-se da cena em que Tapualu busca um gravador cassete portátil para escutar a gravação dos cantos de Mariazinha. Conhecedora daqueles cantos, Tapualu acompanha cantando enquanto escuta a precária gravação que se interrompe a todo momento. As tentativas de seu filho em Ihe explicar o funcionamento do gravador sequer desviam sua atenção, absorta que está nesta escuta. É então esse corpo moldado pelo aprendizado (anterior) dos cantos que entra em ressonância com aquele outro que canta na gravação - e, como nos fenômenos de ressonância acústica, mesmo quando a emissão sonora se interrompe, o canto se mantém ressoando por um tempo na voz de Tapualu.

\section{A forma do canto}

Assim como o gravador de Tapualu, o cinema também seria capaz de fazer operar esse campo de ressonâncias entre o corpo dos sujeitos que cantam e o corpo do espectador conhecedor dos cantos, mas não só. Como já foi dito anteriormente, os Kuikuro encontraram no dispositivo cinematográfico a possibilidade de "guardar" seus cantos, mitos e rituais, ou seja, o cinema seria capaz também de operar no processo de aprendizagem, esta "moldagem" dos corpos à forma dos cantos. Podemos nos perguntar então como o filme poderia engendrar em sua escritura a forma dos próprios cantos.

Em outra cena de transmissão, a mãe de Kanu ensina para sua neta os cantos das Jamugikumalu que ninguém mais se empenha em aprender. Nessa cena, vários trechos dos cantos são intercalados na montagem em campo/contracampo. Se, por um lado, esse procedimento do cinema clássico confere uma contiguidade espacial à cena, por outro, a fragmentação no modo como os cantos são dados a escutar revela a descontinuidade temporal inerente ao que poderíamos chamar de "decupagem documentária" (BELISÁRIO, 2014). Nesse contraexemplo, observamos como uma forma cinematográfica se impõe sobre a cena sem se deixar tensionar pela forma como os próprios cantos mobilizam a relação "ficcionalizada" por tal procedimento.

Não há dúvida de que uma filmagem em plano-sequência, como nas performances rituais da segunda parte do filme, ao sustentar a duração dos cantos, inscreveria claramente no espaço sonoro da cena as figuras musicais que os cantos apresentam. Mas essa não parece ser a única condição para que a forma dos cantos apareçam como elemento presente na escritura do filme. A última cena da primeira parte do filme é um exemplo nesse sentido. 
Sob luz do crepúsculo, um grupo de mulheres descansa e conversa no centro da aldeia. Uma delas passa a ensinar um novo canto para Aulá. A câmera se aproxima para captá-lo de perto. Enquanto canta, a mulher marca o contorno rítmico da música percutindo o dedo na palma da mão. Pela primeira vez, um canto é traduzido pela legenda do filme:

\author{
Jawahiká me disse \\ Matulá me disse \\ Jawahiká me disse assim \\ [eu disse assim] \\ vou tomar banho, eu vou \\ vou me arrumar, eu vou \\ vou tomar banho, eu vou \\ vou me arrumar, eu vou
}

Enquanto as mulheres se preparam para formar o bloco coreográfico, a câmera se posiciona à frente do grupo a uma curta distância. Aulá é quem toma a dianteira do canto para darem início a essa performance. A câmera acompanha o movimento do bloco fixa em seu eixo, deixando-o se distanciar com o canto e a dança. No plano seguinte, a câmera já está à frente das mulheres, movimentando-se com elas em direção à trilha que leva à lagoa, circundando-as. No terceiro plano, a câmera salta novamente à frente do bloco para enquadrar Aulá e Kehesu bem de perto. Em toda esta cena, também decupada no momento mesmo em que a performance ocorre, não há ruptura na continuidade temporal do canto. Isso porque a montagem parte precisamente da estrutura do canto para constituir a unidade da cena.

Como podemos escutar nessa performance, não só o canto é repetido ao longo de toda a cena, como a sua própria forma denota um território musical bastante distinto da musicalidade ocidental do tempo linear, evolutivo, da monumentalidade e do progresso. Nesse outro território (que os musicólogos ocidentais chamam de música modal),

as melodias participam da produção de um tempo circular, recorrente, que encaminha para a experiência de um não tempo ou de um 'tempo virtual', que não se reduz à sucessão cronológica nem à rede de causalidades que amarram o tempo social comum [...] isso se faz através do envolvimento coletivo e integrado do canto, do instrumental e da dança, através da superposição de figuras rítmicas assimétricas no interior de um pulso fortemente definido, e através da subordinação das notas da escala a uma tônica fixa, que permanece como um fundo imóvel, explícito ou implícito, sob a dança das melodias (WISNIK, 1989, p. 78).

O canto Auga Imitoho ("Canto do peixe Auga para ser cantado no final da madrugada"), que faz parte do ritual feminino Tolo, poderia ser transcrito analiticamente da seguinte maneira ${ }^{5}$ (Figura 2):

5 Algumas observações acerca desta transcrição analítica: As linhas horizontais, assim como na notação ocidental, descrevem as alturas em que as "notas"/sílabas são cantadas. Ao contrário da pauta ocidental, elaborada a partir de uma concepção diatônica da música, preferimos manter entre as linhas sempre o mesmo intervalo (aproximadamente um tom). A linha mais espessa representa uma espécie de "acoplamento tonal". Conforme explicou um experiente mestre de cantos do Alto Xingu, "é como um 'buraco' para o qual escorregam bolas" (Yawa'ikumã Kamayurá apud MENEZES BASTOS, 1990, p. 402). As "notas" não carregam nenhum índice de duração como na notação ocidental, elas marcam tão somente o momento de seu ataque, que está diretamente ligado à "métrica" definida pela divisão silábica e pelo acento regular produzido pela percussão do pé direito no chão. 

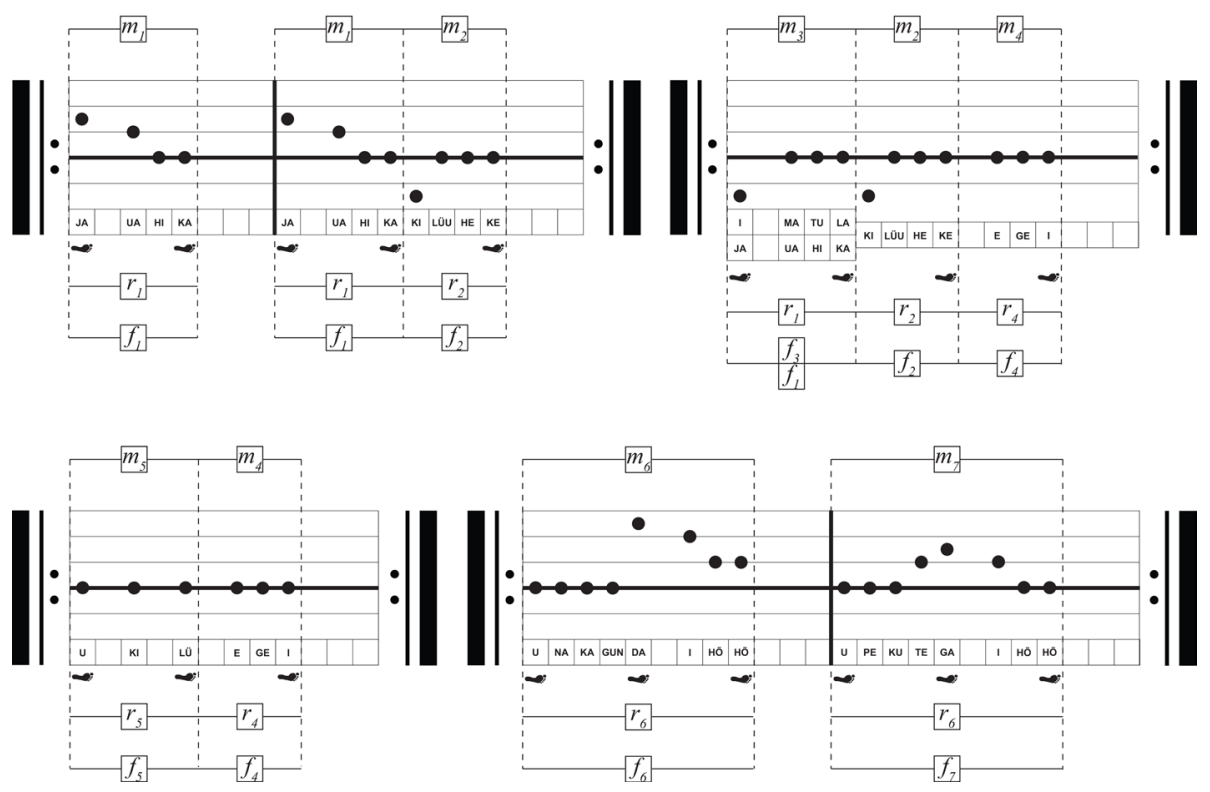

Fig.2. Transcrição analítica do canto Auga Imitoho. Fonte: Elaborada pelo autor.

Com relação à macroestrutura de repetições, representadas pelos ritornelos, no segundo deles há uma variação fonética quando é repetido - inicia-se com "i Matula" $\left(f_{3}\right)$ e, na volta, com "Jauahika" $\left(f_{1}\right)$. Todos os demais se repetem integralmente. Com relação às repetições microestruturais (interiores aos ritornelos), podemos identificar uma recorrência do segmento melódico-rítmico-fonético $m_{1}-r_{1}-f_{1}$ no primeiro deles. No segundo, além da repetição do segmento $m_{2}-r_{2}-f_{2^{\prime}}$ presente no primeiro ritornelo, percebe-se que o segmento melódico $m_{3}$ tem, como elemento rítmico, o mesmo segmento $r_{1}$ que se repetira anteriormente, assim como na repetição do segmento fonético $f$, na volta deste segundo ritornelo, conforme notamos. No terceiro deles, repete-se o segmento $m_{4}{ }^{-} r_{4}-f_{4^{\prime}}$ presente no segundo. O último ritornelo é formado pela repetição de um mesmo segmento rítmico $r_{6}$ com uma variação fonética "unakagunda/upekutega" $\left(f_{6} / f_{7}\right)$ na metade inicial do segmento e uma variação melódica $\mathrm{m}_{6} / \mathrm{m}_{7}$ na sua metade final.

Com relação às variações, podemos notar um movimento interessante ao longo dos três primeiros ritornelos. Se considerarmos que o segmento $m_{1}-r_{1}-f_{1}$ juntamente com o segmento composto pelas três sílabas "vazias" (---), que o precede, formam uma frase, poderíamos dizer que, quando esta se repete, ainda no primeiro ritornelo, há uma espécie de fissura entre estes segmentos, fazendo surgir um novo pulso percussivo acompanhado pelo segmento $m_{2}-r_{2}-f_{2}$. E assim na passagem realizada pelo ritornelo, em que há precisamente uma repetição da frase rítmica anterior $\left(r_{1}+r_{2}+---\right)$ com uma fissura 
entre o segmento das sílabas "vazias" e $m_{2}-r_{2}-f_{2^{\prime}}$ de onde surge um novo pulso percussivo acompanhado pelo segmento $m_{4}-r_{4}-f_{4}$. Na passagem pelo terceiro ritornelo, parece acontecer o movimento contrário. Os dois segmentos finais da frase do ritornelo que o antecede se mantém inalterados, mas há a supressão do pulso e do segmento $m_{2}-r_{2}-f_{2^{\prime}}$ assim como apresenta um segmento inicial $\left(m_{5}-r_{5}-f_{5}\right)$ diferente de todos os outros.

Como vínhamos argumentando, o filme passa a participar deste outro tempo fabricado pelo canto, não só por inscrever no seu plano sonoro esse complexo sistema de repetições e variações de figuras rítmicas, melódicas e fonéticas, mas por fazer modular sua própria escritura em ressonância com esse outro campo sonoro. Seria preciso agora analisar como o filme elabora sua mise-en-scène documentária, essa "dança a dois" (COMOLLI, 2008) entre a câmera e as mulheres em suas performances rituais.

\section{A câmera e o ritual}

O verbo que os Kuikuro utilizam para se referirem à ação de filmar é ahehi. Tradicionalmente, esse termo designa "uma modalidade específica de representação que inclui o desenho de mapas, diagramas, gráficos ou cartas" (FRANCHETTO, 2010, p.62, nota 6). ${ }^{6}$ Partimos então desta noção para analisar como a câmera elabora seu "traçado" no pátio da aldeia enquanto as mulheres executam suas performances rituais. Uma das sequências exemplares da maneira como a câmera se posiciona e se movimenta em relação à coreografia das mulheres no filme é a cena do Jamugikumalu Ahugagülü (Figura 3).
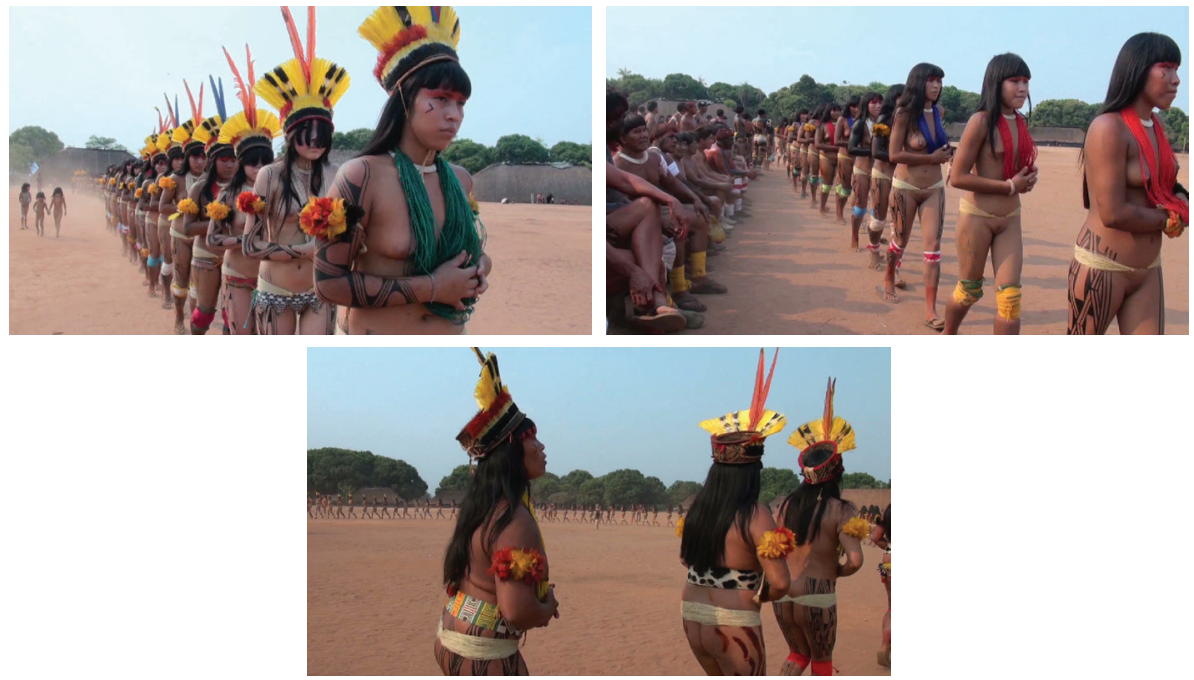

Fig.3. Performance ritual do Jamugikumalu Ahugagülü. Fonte: Fotogramas do filme As Hipermulheres (2011).

6 Posteriormente, este termo passou a designar também a escrita. 
Enfeitadas com sues colares, cintos, joelheiras e pinturas corporais, as mulheres deixam a casa do "dono do ritual" dançando em direção ao pátio central da aldeia. Sua dança consiste em percutir o pé direito no chão e movimentar pendularmente os braços unidos pelas mãos à altura do abdômen. ${ }^{7}$ As belas jovens que encabeçam a fila se distinguem das outras mulheres pelos adornos que portam - cocares e braçadeiras de plumas. Algumas delas exibem também corpos despigmentados e longas franjas que lhes cobrem parte do rosto. A câmera acompanha o movimento da fila de modo a manter estas jovens em campo, descrevendo o trajeto representado no diagrama (Figura 4).

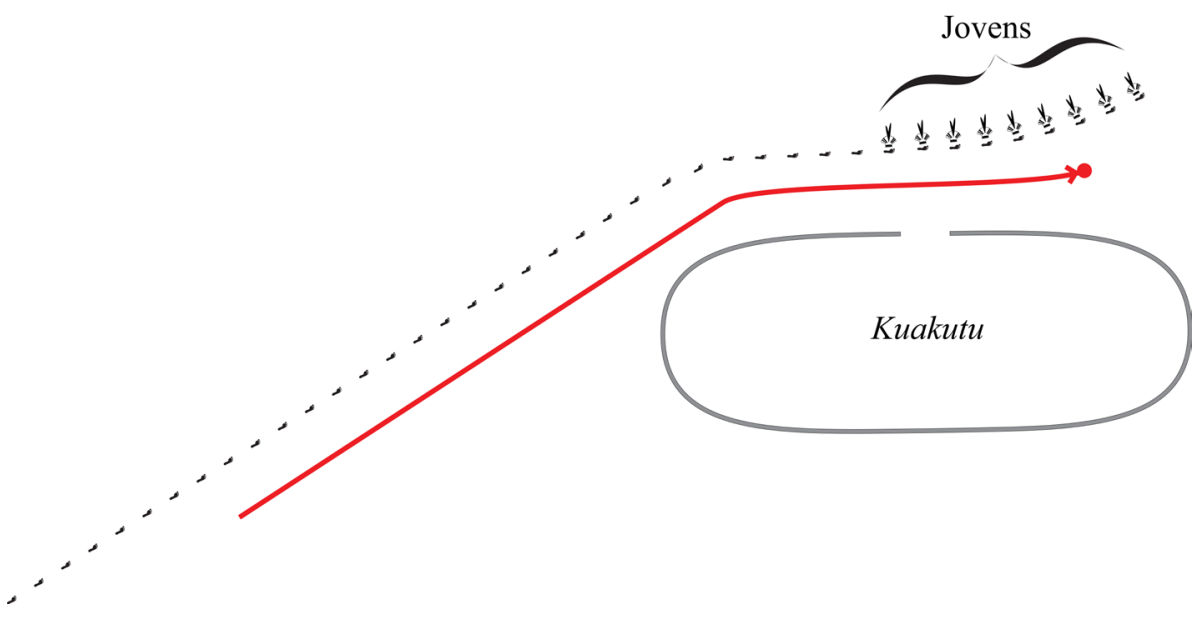

Fig.4. Trajetória da câmera e da forma coreográfica do Jamugikumalu Ahugagülü - primeira parte. Fonte: Elaborada pelo autor.

Ao alcançar a área à frente da Kuakutu, ${ }^{8}$ onde os espectadores estão posicionados, a fila se curva dando início a uma grande formação coreográfica circular. Nesse momento, a câmera deixa de acompanhá-las, posicionando-se num ponto a partir do qual é possível observar (e escutar) tanto os espectadores quanto a fila das mulheres que passam dançando. Além da percussão dos pés (e dos comentários masculinos), é possível ouvir o som brilhante dos guizos metálicos que algumas delas levam presos aos seus tornozelos. De longe, vem surgindo um grupo de mulheres também adornadas com cocares e braçadeiras de plumas. Elas cantam e dançam um dos cantos que as mulheres míticas executaram para se transformar nas Itaõ Kuêgü, as Hipermulheres, conforme a narrativa

7 Os Kuikuro chamam esse movimento de percussão do pé nas danças rituais (tanto masculinas quanto femininas) de egitsainhe e o balançar dos braços de amangakenügü - movimento exclusivamente feminino que poderia ser traduzido como "balançar o seio".

8 Casa que se localiza no centro da aldeia, onde ficam escondidas as flautas Kagutu, cuja visão é interdita às mulheres. Não parece haver tradução precisa para o termo Kuakutu, de origem aruak (kuwakuho), sendo traduzido livremente pelos Kuikuro como "casa dos homens" ou "casa das flautas sagradas", ou ainda "casa dos rituais" (MEHINAKU, 2010, p.145). 
contada anteriormente por Kanu e Kamankgagü no filme. O canto vai tomando completamente o espaço sonoro da cena. Quando Kanu, a mestre de cantos Jamugikumalu - destacada das outras pela pintura de urucum que lhe cobre a franja -, alcança o primeiro plano, a câmera volta a acompanhar o movimento coreográfico de forma a mantê-la em campo (Figura 5), e assim seu canto.

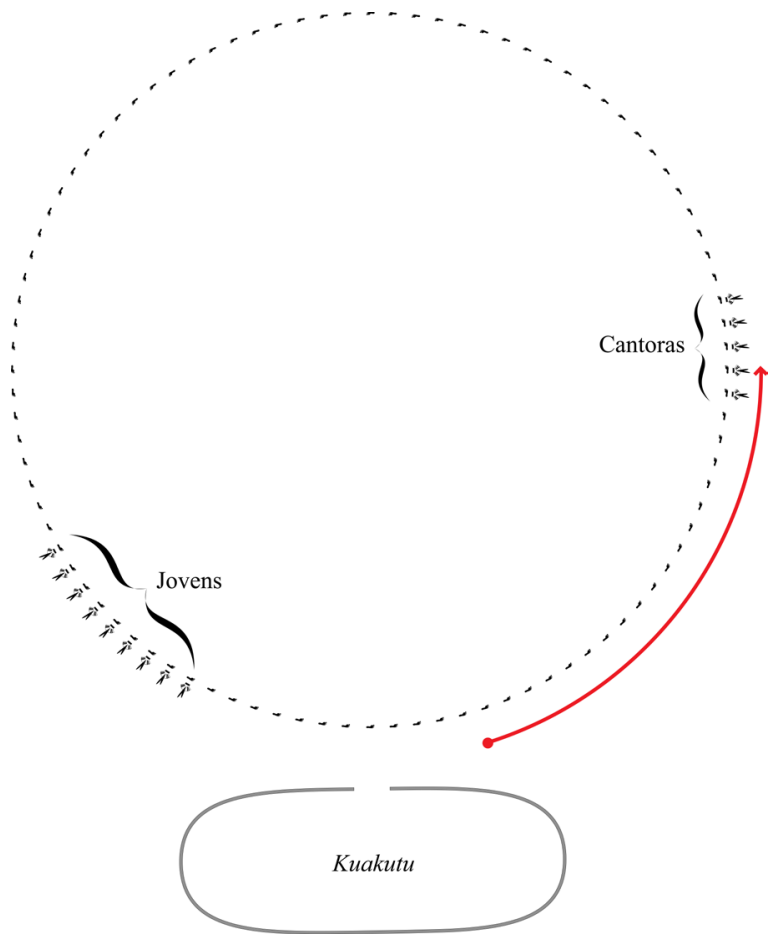

Fig. 5. Trajetória da câmera e da forma coreográfica do Jamugikumalu Ahugagülü - segunda parte. Fonte: Elaborada pelo autor.

Conforme vimos nessa cena, o corpo coreográfico apresenta dois polos devidamente auto-sublinhados (FRANCE, 1998) pelos cocares e braçadeiras: as jovens agiketi ("franja cortada") e masope ("que já teve menstruação") que encabeçam a fila; e as cantoras (igisü oto) que são uma espécie de motor ou núcleo músico-coreográfico.

No caso das jovens, sua performance no ritual marca o seu gradual retorno para a sociedade após a reclusão pubertária, conforme descreve a antropóloga Bruna Franchetto:

A menina, ao menstruar pela primeira vez, é definida coletivamente e publicamente como masope (...), é retirada da visibilidade social durante um período que pode variar de alguns meses a dois anos, dependendo de expectativas e status de seu grupo familiar [...] A pele deve manter-se perfeitamente branca 
na escuridão da reclusão da qual só é permitido sair por poucos minutos no começo da noite ou quando a jovem se apresenta nas danças do apogeu dos rituais - exposições de seu corpo belo e que preanunciam gradativamente seu retorno à sociedade já como mulher literalmente feita (FRANCHETTO, 1996, p.37-38).

As jovens à frente da fila exerceriam então uma força de atração "visual" nos espectadores do ritual. Como podemos ver no diagrama que descreve a primeira parte deste plano-sequência (Figura 4), ao se movimentar para manter em primeiro plano as belas jovens, a câmera de Monai Kuikuro traça um percurso no pátio cerimonial bastante similar ao do movimento coreográfico. Capturada pelas forças que agem sobre o olhar dos espectadores da aldeia, a câmera passa a constituir com o ritual uma figura fílmica em ressonância com a figura coreográfica. O campo visual que o filme instaura, entretanto, não se confunde nem com o ponto de vista dos espectadores da aldeia, posicionados em frente a Kuakutu, nem com o das mulheres que dançam em cena. Acoplada ao corpo do cinegrafista, a câmera faz deste, outro corpo posto em relação no ritual, cujas afecções e percepções exigem para ele outro lugar no próprio ritual - é preciso se aproximar ao máximo das jovens para dar a ver, em primeiro plano, seus belos corpos pintados e adornados. Essa diferença com relação aos demais corpos (e lugares) no ritual fica evidente quando a câmera se posiciona entre os espectadores e as mulheres em performance na cena que analisamos.

Como vimos na figura coreográfica do Jamugikumalu Ahugagülü, destacam-se ali dois polos: um eminentemente visual - as jovens - e outro eminentemente sonoro (ou musical) as cantoras. Na segunda parte desse plano-sequência, quando a câmera deixa sua posição próxima a Kuakutu e retoma seu movimento no pátio da aldeia, são os afetos sonoro-musicais veiculados pelos cantos que parecem exercer uma força sobre a câmera e seu microfone.

Como na performance do Auga Imitoho, ao se movimentar de modo a manter em cena o canto executado pelas cantoras na forma coreográfica, a câmera passa a inscrever o filme naquele outro tempo fabricado pela música. De dentro deste tempo pulsado pela percussão dos pés em performance e pelas repetições que constituem o canto, o filme faz ouvir aqueles sutis movimentos de variação: rastros sonoros das forças que a música é capaz de carregar.

Esse percurso da câmera, que desenha no pátio da aldeia um movimento em ressonância com o movimento da forma coreográfica, pode ser percebido também em outras cenas de As Hipermulheres, como por exemplo nas performance do "Canto do Tatu", em que as mulheres dançam em fila com as mãos nas cinturas umas das outras. Não há, nessa outra formação coreográfica, polos sublinhados por adornos distintivos, com exceção do bastão percutido no chão pela mulher que lidera a fila. Todas as mulheres (incluindo-se aí as crianças) cantam. A câmera se posiciona à frente da fila, serpenteando com ela pelo pátio da aldeia (Figura 6). 


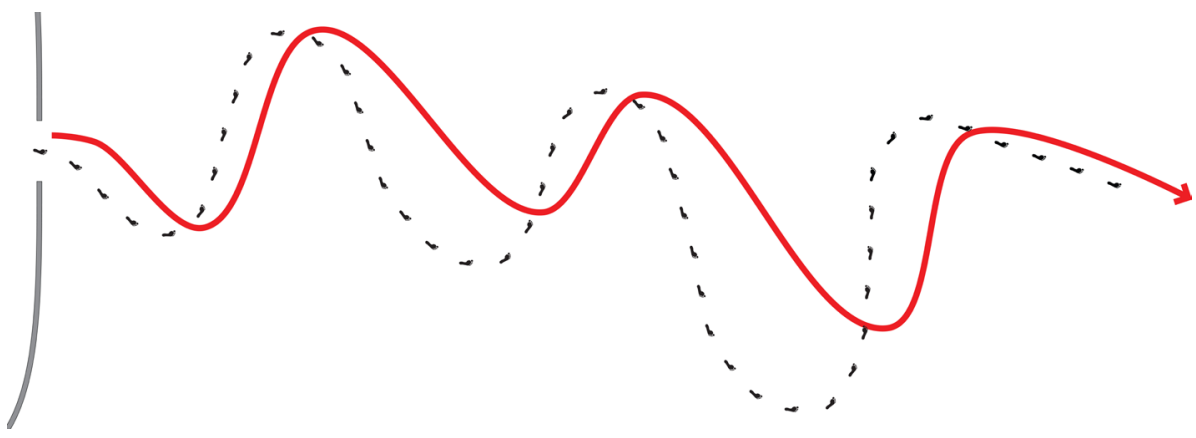

Fig.6.Trajetória da câmera e da forma coreográfica do "Canto do Tatu" (Kagutaha lgisü).

Fonte: Elaborada pelo autor.

Em todas essas cenas, verifica-se o fenômeno de ressonância entre a câmera e a forma coreográfica, o que não significa que elas descrevam um mesmo movimento. A diferença entre os trajetos apontam para uma diferença entre os próprios corpos em jogo no ritual, cujas afecções e percepções implicam maneiras próprias de entrar em ressonância nesse agenciamento.

\section{Considerações finais}

Como dissemos, há pouco mais de uma década temos visto surgir no Brasil uma vasta produção fílmica que dá a ver e ouvir o mundo ameríndio de uma forma completamente nova. Esses filmes produzidos no âmbito de oficinas de formação audiovisual, ou realizados autonomamente pelos cineastas indígenas, colocam desafios não só para o campo dos Estudos do Cinema como para a própria Antropologia Visual ou Fílmica.

Além da investigação bibliográfica no campo do cinema, recorremos a etnografias acerca dos Kuikuro e do Alto Xingu. Realizamos também uma breve pesquisa de campo de dois meses na aldeia onde o filme foi realizado. Com esse gesto de invenção metodológica (no campo dos Estudos do Cinema), buscamos trazer para dentro das análises alguns traços próprios da descrição etnográfica. Contudo, essas impressionantes "etnografias filmadas", que os cineastas indígenas realizam dos seus próprios rituais, oferecem mais que um conjunto de informações ou dados registrados em suporte fílmico. Esses filmes propõem também (e principalmente) modos de elaboração da mise-en-scène cinematográfica capazes de fazer inscrever ali forças e vetores em jogo em seus rituais. Nossa análise buscou então identificar e descrever alguns deles, partindo do canto como uma espécie de elemento catalisador das interações entre filme e ritual (mesmo quando o ritual não passa de uma sutil maquinação dos corpos em cena). A ressonância surge então como figura capaz de caracterizar as diversas maneiras como distintos corpos (dentre eles a própria câmera) são mobilizados nesse regime da intensidade próprio ao ritual. 
Como vimos, os cantos que escutamos em cena são formados por um complexo sistema de repetições e variações que relacionam figuras melódicas, fonéticas e rítmicas num jogo de ressonâncias e defasagens mobilizando e agenciando o próprio corpo das mulheres que cantam. O balanço pendular dos braços, a percussão dos pés e o movimento coreográfico são então componentes deste grande sistema de ressonâncias que, em última instância, é o próprio ritual. E quando aquele outro agenciamento, a câmera-cinegrafista, passa a habitar esse tempo e esse espaço fabricados pelos cantos e pelas danças no ritual, é o próprio filme que se transforma. O ritual se lança em direção ao filme com suas forças de captura e vetores de ressonância, assim como o filme se lança no ritual instaurando ali outro ponto de vista e de escuta. Esse tipo de agenciamento que percebemos em As Hipermulheres é certamente uma figura daquilo que se tem chamado de filme-ritual.

Bernard Belisário é doutorando no Programa de Pós-graduação em Comunicação Social da UFMG. Trabalhou na emissora de televisão Rede Minas, onde atuou como diretor de documentários no Núcleo de Registro do Patrimônio Imaterial. É montador, finalizador e colorista de cinema, além de presidente da ONG Associação Imagem Comunitária.

bernardbelisario@gmail.com

\section{Referências}

ALBÉRA, François. Mise en scène et rituels sociaux. In: AUMONT, Jacques (org.). La mise en scène. Bruxelles: De Boeck \& Larcier, p. 219-231, 2000.

AUMONT, Jacques; MICHEL, Marie. Dicionário teórico e crítico de cinema. Campinas: Papirus, 2003 [2001].

BELISÁRIO, Bernard. As Hipermulheres: cinema e ritual entre mulheres, homens e espíritos. Dissertação de Mestrado: PPGCOM/UFMG, 2014.

Ressonâncias entre cinema e ritual em As Hipermulheres. Trabalho apresentado no $\mathbf{1 9}^{\circ}$ Encontro da Sociedade Brasileira de Estudos de Cinema e Audiovisual. Campinas: Unicamp, 20 a 23 de outubro de 2015 .

COMOLLI, Jean-Louis. Ver e poder: a inocência perdida: cinema, televisão, ficção, documentário. Belo Horizonte: Editora UFMG, 2008 [2004].

DELEUZE, Gilles; Félix GUATTARI. Mil platôs: capitalismo e esquizofrenia, vol. 4. São Paulo: Ed. 34, 1997 [1980].

FAUSTO, Carlos. No registro da cultura. In: ARAÚJO, Ana Carvalho Ziller (org.). Vídeo nas aldeias 25 anos: 1986-2011. Olinda: Vídeo nas Aldeias, p. 160-168, 2011. 
FRANCE, Claudine de. Cinema e Antropologia. Campinas: Ed. Unicamp, 1998 [1982].

FRANCHETTO, Bruna. Mulheres entre os Kuikúro. Estudos Feministas, v. 4, n. 1, p. 35-54, 1996.

Bridging linguistic research and linguistic documentation: the Kuikuro experience (Brazil). In: FARFÁN, José Antonio Flores; RAMALLO, Fernando (orgs.). New perspectives on endangered languages: bridging gaps between sociolinguistics, documentation and language revitalization. Amsterdam; Philadelphia: John Benjamins Publishing Company, p. 49-54, 2010.

HECKENBERGER, Michael. Estrutura, história e transformação: a cultura xinguana na longue durée, 1000-2000 d.C. In: FRANCHETTO, Bruna; HECKENBERGER, Michael (orgs.). Os povos do Alto Xingu: história e cultura. Rio de Janeiro: UFRJ, p. 21-62, 2001.

MEHINAKU, Mutua. Tetsualü: pluralismo de línguas e pessoas no Alto Xingu. Dissertação de Mestrado: PPGAS/MN/UFRJ, 2010.

MENEZES BASTOS, Rafael José de. A Festa da Jaguatirica: uma partitura crítico-interpretativa. Tese de Doutorado: PPGAS/USP, 1990.

WISNIK, José Miguel. O som e o sentido. São Paulo: Companhia das Letras. 1989.

Artigo recebido em junho e aprovado em outubro de 2015. 